\title{
Lipid-lowering drugs (statins) and peripheral neuropathy
}

\author{
Mohammadreza Emad ${ }^{1}$, Hosein Arjmand ${ }^{2}$, Hamid Reza Farpour ${ }^{3}$, Bahareh Kardeh ${ }^{4}$
}

${ }^{1}$ M.D., Physiatrist, Professor, Bone and Joint Diseases Research Center, Department of Physical Medicine \& Rehabilitation, Faculty of Medicine, Shiraz University of Medical Sciences, Shiraz, Iran

${ }^{2}$ M.D., Physiatrist, Shiraz Geriatric Research Center, Department of Physical Medicine \& Rehabilitation, Faculty of Medicine, Shiraz University of Medical Sciences, Shiraz, Iran

${ }^{3}$ M.D., Physiatrist, Assistant Professor, Shiraz Geriatric Research Center, Department of Physical Medicine \& Rehabilitation, Faculty of Medicine, Shiraz University of Medical Sciences, Shiraz, Iran

${ }^{4}$ M.D., Research Assistant, Bone and Joint Diseases Research Center, Clinical Neurology Research Center, Shiraz Medical School, Shiraz University of Medical Sciences, Shiraz, Iran

\section{Type of article: Original}

\begin{abstract}
Background and aim: Peripheral neuropathy is a disorder with often unknown causes. Some drugs, including statins, are proposed to be among the causes of peripheral neuropathy. This study aimed at evaluating this condition by electrodiagnostic study among patients who had received statins.

Methods: This case-control study was conducted in Shiraz, Iran in 2015, and included 39 patients aged 35-55 who had received statins for at least 6 months, and 39 healthy matched controls. Using electrodiagnosis, the sensory and motor wave features (amplitude, latency and nerve conduction velocity) of the peripheral nerves (Median, Ulnar, Tibial, Sural, and Peroneal) were evaluated among the subjects. Data were analyzed using SPSS software and $\mathrm{p}<0.05$ was considered statistically significant.

Results: Regarding the occurrence of neuropathy, there were no significant differences in any of the definitions presented for peripheral neuropathy. However, the difference was close to significance for one definition [2 abnormalities in 2 nerves $(\mathrm{p}=0.055)]$. Regarding mean values of the features, significant differences were observed in two features: amplitude of the peroneal motor nerve $(\mathrm{p}=0.048)$ and amplitude of the sural sensory nerve $(\mathrm{p}=0.036)$.

Conclusion: Since statins are widely used, awareness regarding their side-effects would lead to better treatment. Even though no significant differences were found between the groups regarding the occurrence of peripheral neuropathy, there were significant differences in amplitudes of the sural sensory response and the peroneal motor response. This indicates the involvement of peripheral nerves. Therefore, we recommend that patients and physicians should be informed about the possible symptoms of this condition.

Keywords: Hydroxymethylglutaryl-CoA reductase inhibitors, Peripheral nervous system disease, Electrodiagnosis
\end{abstract}

\section{Introduction}

Drug-induced neuropathy is one of the main causes of peripheral neuropathies. This is of great importance because through an early diagnosis, significant recovery will occur after stopping the prescribed medication and administering the proper treatment. On the other hand, in many cases there is no specific treatment for idiopathic neuropathies (1). Neuropathic symptoms include sensory, motor and autonomic dysfunctions which depend on the type of the peripheral nerve involvement. Sensory symptoms include prickling, tingling, bunch-up and numbness. Patients with acquired neuropathy usually complain of positive neuropathic sensory symptoms while such symptoms

\section{Corresponding author:}

Assistant Professor Dr. Hamid Reza Farpour, Shiraz Geriatric Research Center, Department of Physical Medicine \& Rehabilitation, Faculty of Medicine, Shiraz University of Medical Sciences, Shiraz, Iran.

Tel: +98.9171179541, Fax:+98.7132319040, Email: farporh@sums.ac.ir

Received: April 07, 2017, Accepted: January 02, 2018, Published: March 2018

iThenticate screening: October 16, 2017, English editing: February 10, 2018, Quality control: February 15, 2018

This article has been reviewed / commented by four experts

(C) 2018 The Authors. This is an open access article under the terms of the Creative Commons Attribution-NonCommercialNoDerivs License, which permits use and distribution in any medium, provided the original work is properly cited, the use is non-commercial and no modifications or adaptations are made. 
are rarely mentioned in hereditary polyneuropathies $(2,3)$. Pain could have toxic, metabolic or ischemic causes. In such cases, symptoms like burning, freezing or throbbing could be experienced. Motor symptoms usually manifest as paresis. Autonomic symptoms include diarrhea, syncope, light-headedness, urinary problems, early satiety, constipation, dry mouth and dry eyes, diminished or excessive perspiration, and erectile dysfunction (2). Fortunately, drug-induced neuropathies are not that frequent (2-4\%) (4). When acute side-effects manifest following consumption of a drug, it would be easy to make the link (most side-effects appear in this manner), but in cases such as peripheral neuropathy, it would take months or even years before any symptoms appear; hence, it is farfetched to find this kind of relation $(1,3,5)$. Dying-back axonal involvement is the most common type of peripheral neuropathy following medication; since the neuronal cell body and proximal axon are intact, the patient recovers after stopping the stimulus, for instance cutting off medication. However, some drugs might involve the peripheral nerves in other ways, for instance involvement of myelin, autonomic nerves and nerve roots (6). Chemotherapy drugs, Metronidazole, Amiodarone, Hydralazine, Enalapril, Phenytoin, Allopurinol, and Colchicine might induce peripheral neuropathy $(1,4)$. However, the role of statins in peripheral neuropathy has not yet been definitively proven (7), and many studies have merely included case reports involving this condition $(8,9)$. Statins as Hydroxymethyl-CoA Reductase (HMG-CoA) inhibitors lower the plasma cholesterol, especially Low-density lipoprotein (LDL), following the inhibition of intracellular cholesterol production $(6,10)$. Treatment indications with statins are hypercholesterolemia and prevention of cardiovascular diseases (11) that can lead to the reduction of morbidity and mortality (6). Therefore, considering their extensive usage, it is necessary to be aware of their side-effects. Muscle diseases are the most common side-effects of statins, which could manifest ranging from mild muscle weakness to severe rhabdomyolysis $(10,12-14)$. Peripheral neuropathy is a probable side-effect of these drugs. Due to the intrusive role of these drugs in the production of cholesterol, they might change the function and integrity of cell membranes, in which cholesterol plays a key role (15). Meanwhile, statins also inhibit an important enzyme in mitochondrial respiration named ubiquinone (Coenzyme Q10), which could in turn change the neurons' energy consumption $(3,6,15-17)$. These are the probable mechanisms of the peripheral neuropathy. Electrodiagnostic tests are amongst the most important methods for diagnosis of peripheral neuropathy. These tests are used to confirm peripheral neuropathy, diagnose the axon or myelin involvement or both of them, as well as classify neuropathy as sensory, motor and sensorimotor, determining the location of the nerve injury and revealing the severity of peripheral nerve involvement $(2,18)$. Based on the pathophysiology of this adverse effect and our clinical experience, we attempted to evaluate the probable peripheral nerve dysfunctions amongst native Iranian patients with long-term history of statin consumption based on electrodiagnosis. To the best of our knowledge, there are no previous similar studies in this field.

\section{Material and Methods}

\subsection{Patients and Settings}

In this case-control study, a total of 39 qualified patients (sample size determined according to previous studies) were enrolled in a case group via simple random sampling. The study population was those who visited the physical medicine and rehabilitation outpatient clinics of Shiraz University of Medical Sciences, Shiraz, Iran in 2015. The control group consisted of 39 cases selected through the patients' relatives, friends and colleagues, who had never consumed such drugs and had never complained about any signs of peripheral neuropathy. Demographic data such as age, sex, height and weight of both groups were selected to be similar.

\subsection{Selection criteria}

Inclusion Criteria were age between 35-55 years, daily consumption of at least $10 \mathrm{mg}$ simvastatin, and $10 \mathrm{mg}$ atorvastatin and $20 \mathrm{mg}$ lovastatin for more than six consecutive months. Exclusion Criteria were consumption of any drugs that have proven to cause peripheral neuropathy; history of cancer or chemotherapy, trauma and fractures in the upper and lower limbs, diabetes, hereditary neuropathies, anatomical and hereditary disorders in the upper and lower limbs, rheumatic disease and vasculitis, hepatopathy, digestive diseases such as celiac and inflammatory bowel syndrome, respiratory disease, thyroid disease, paraproteinemia, metabolic disease, exposure to various toxins and heavy metals, alcohol consumption, Lyme disease, HIV/AIDS, tuberculosis, leprosy, syphilis, B12 deficiency, uremia, space-occupying lesions in the upper and lower limbs, active radiculopathies; and finally various entrapment neuropathies such as carpal tunnel syndrome.

\subsection{Procedure}

After clinical examination of all subjects by a physician, especially their neuro-musculoskeletal systems and if they met the inclusion criteria, electrodiagnostic tests were performed by a specialist in physical medicine and rehabilitation $(18,19)$. Outcome evaluation was blinded. The calibration of the system was ensured. The nerve 
conduction study (NCS) was performed in normal room temperature $\left(24{ }^{\circ} \mathrm{C}\right)$; while temperatures of the upper and lower limbs were at the standard degree for the test, which is $34{ }^{\circ} \mathrm{C}$ and $32{ }^{\circ} \mathrm{C}$, respectively. Also, the limbs were not wet and no perspiration was observed. The EMG machine in use was a Medelec Synergy electromyography instrument (VIASYS HealthCare, Surrey, UK) and surface electrodes were used for both recording and stimulation. The grounding plate was placed on the same limb and supramaximal electrical stimulation was induced manually. Stimulation lasted for $0.1 \mathrm{~ms}$ at the frequency of 1-0.2 Hz. Machine settings were as follows: Sweep speed: 2 $\mathrm{ms} /$ division; Sensitivity for sensory waves: $50 \mu \mathrm{v} /$ division; Sensitivity for motor waves: 1mv/division; Filter: $2 \mathrm{~Hz}-2$ $\mathrm{kHz}$. Waves were evaluated for the tibial, peroneal, ulnar, and median motor nerves, as well as median, ulnar and sural sensory nerves. Nerve conduction velocity (NCV) was also measured for median, tibial and peroneal nerves. Placement methods for stimulation and recording electrodes and natural values of amplitude, latency and NCV for motor and sensory nerves of the upper and lower limbs are shown in Table 1. Regarding motor nerve conduction, the recording electrode recorded the compound muscle action potential (CMAP) of the relative muscle. Onset latency was defined as the period from the moment stimulation begins until the first wave was recorded. Regarding sensory nerve conduction, the recording electrode recorded the sensory nerve action potential (SNAP) of the relative muscle. Peak latency was defined as the period from stimulation until the appearance of the negative peak latency. Furthermore, the amplitudes of CMAP and SNAP waves were calculated based on the distance between baseline and the highest peak of the negative wave. We defined the criteria for peripheral neuropathy as below:

1) Two abnormalities (velocity, amplitude, latency) in 2 nerves

2) Two abnormalities in 3 asymmetrical nerves (mononeuritis multiplex)

3) Two abnormalities in 3 symmetrical nerves (polyneuropathy)

Table 1. Placement methods for stimulation and recording electrodes and natural values of amplitude, latency and NCV for motor and sensory nerves of the upper and lower limbs

\begin{tabular}{|c|c|c|c|c|c|}
\hline $\begin{array}{l}\text { Nerve conduction } \\
\text { study }\end{array}$ & Stimulation site & Recording site & Amplitude & $\begin{array}{l}\text { Onset latency } \\
(\mathrm{ms}) \text { site } 1\end{array}$ & $\begin{array}{l}\text { Conduction } \\
\text { velocity }(\mathrm{m} / \mathrm{s})\end{array}$ \\
\hline $\begin{array}{l}\text { Median motor } \\
\text { response }\end{array}$ & $\begin{array}{l}\text { The wrist, somewhere between the palmaris longus and } \\
\text { flexor carpi radialis tendons, } 7 \mathrm{~cm} \text { proximal to recording } \\
\text { site (active electrode) }\end{array}$ & $\begin{array}{l}\text { The abductor pollicis } \\
\text { brevis muscle }\end{array}$ & $\geq 4 \mathrm{mv}$ & $\leq 4.4$ & - \\
\hline $\begin{array}{l}\text { Ulnar motor } \\
\text { response }\end{array}$ & $\begin{array}{l}\text { The wrist, next to the tendon of the flexor carpi ulnaris } \\
\text { muscle, } 7 \mathrm{~cm} \text { proximal to recording site (active electrode) }\end{array}$ & $\begin{array}{l}\text { The abductor digiti } \\
\text { minimi muscle }\end{array}$ & $\geq 6 \mathrm{mv}$ & $\leq 3.3$ & - \\
\hline $\begin{array}{l}\text { Tibial motor } \\
\text { response }\end{array}$ & $\begin{array}{l}\text { Site 1: The medial side of the ankle, higher and behind } \\
\text { the medial malleolus, } 9 \mathrm{~cm} \text { proximal to the recording site } \\
\text { (active electrode); site } 2: \text { the middle section of the } \\
\text { popliteal region, on the popliteal pulse }\end{array}$ & $\begin{array}{l}\text { The abductor } \\
\text { hallucis muscle }\end{array}$ & $\geq 4 \mathrm{mv}$ & $\leq 5.8$ & $\geq 41$ \\
\hline $\begin{array}{l}\text { Deep peroneal } \\
\text { motor response }\end{array}$ & $\begin{array}{l}\text { Site 1: The ankle, slightly lateral to the tendon of the } \\
\text { tibialis anterior muscle, } 9 \mathrm{~cm} \text { proximal to the recording } \\
\text { site (active electrode); site } 2 \text { : under the head of the } \\
\text { fibula, one or two fingerbreadths lower }\end{array}$ & $\begin{array}{l}\text { The extensor } \\
\text { digitorum brevis } \\
\text { muscle }\end{array}$ & $\geq 2 \mathrm{mv}$ & $\leq 6.5$ & $\geq 44$ \\
\hline $\begin{array}{l}\text { Median sensory } \\
\text { response }\end{array}$ & $\begin{array}{l}\text { Site 1: the wrist, somewhere between the palmaris longus } \\
\text { and flexor carpi radialis tendons, } 14 \mathrm{~cm} \text { proximal to } \\
\text { active electrode; site } 2 \text { : the palm, } 7 \mathrm{~cm} \text { proximal to the } \\
\text { recording site (active electrode) }\end{array}$ & $\begin{array}{l}\text { Palmar surface of the } \\
\text { middle finger }\end{array}$ & $\geq 20 \mu \mathrm{v}$ & $\leq 3.5$ & $\geq 50$ \\
\hline $\begin{array}{l}\text { Ulnar sensory } \\
\text { response }\end{array}$ & $\begin{array}{l}\text { The medial side of the wrist, next to the tendon of the } \\
\text { flexor carpi ulnaris muscle, } 11 \mathrm{~cm} \text { proximal to the } \\
\text { recording site (active electrode) }\end{array}$ & $\begin{array}{l}\text { Palmar surface of the } \\
5^{\text {th }} \text { finger }\end{array}$ & $\geq 17 \mu \mathrm{v}$ & $\leq 3.1$ & - \\
\hline $\begin{array}{l}\text { Sural sensory } \\
\text { response }\end{array}$ & $\begin{array}{l}\text { Posterior leg, } 14 \mathrm{~cm} \text { more proximal from the recording } \\
\text { site, somewhere between the posterior and lateral section } \\
\text { of the calf muscle }\end{array}$ & $\begin{array}{l}\text { Behind the lateral } \\
\text { malleolus }\end{array}$ & $\geq 6 \mu \mathrm{v}$ & $\leq 4.4$ & - \\
\hline
\end{tabular}

$\mathrm{mV}$ : millivolt; ms: millisecond; m/s: meter/second; $\mu \mathrm{v}$ : microvolt

\subsection{Statistical analysis}

The obtained values were analyzed using SPSS version 18 (SPSS Inc., Chicago, Illinois, USA). Descriptive statistics (means and standard deviations) were reported for each nerve conduction value. The t-test, Cochran's Q test and Fisher`s exact test were used for analysis of the results. $\mathrm{P}<0.05$ was considered statistically significant.

\subsection{Ethics}

Written consent was obtained from all participants after explaining the study objectives. The study protocol was in accordance to the Helsinki Declaration of Bioethics and was approved by institutional review board. 


\section{Results}

The case group consisted of 39 individuals (25 men and 14 women) with a mean age of 47 and age range of 37-55 years. Average period of statin consumption in this group was eight months. There were 39 individuals ( 21 men and 18 women) in the control group with an average age of 49 and age range of 35-55. All values obtained from the NCS (amplitude, latency and NCV) were compared with the normal values for each nerve; results are displayed in Table 2. We calculated the means for different wave features (amplitude, latency and NCV), and made a comparison using an independent t-test, as shown in Table 3. According to Table 3, the mean differences were only significant for amplitudes of the peroneal motor nerve $(p=0.048)$ and sural sensory nerve $(p=0.036)$; regarding amplitude of the median sensory nerve $(p=0.058)$, the amplitude of the ulnar sensory nerve $(p=0.070)$, the amplitude of the tibial motor nerve $(\mathrm{p}=0.068)$ and the latency of the ulnar sensory nerve $(\mathrm{p}=0.064)$, even though statistically insignificant, were worth considering. No significant differences were observed in other cases.

Table 2. Comparison of the case and control groups based on the occurrence of neuropathy

\begin{tabular}{|l|l|l|l|}
\hline Definition for neuropathy & Control $(\mathrm{n}=39)$ & Case $(\mathrm{n}=39)$ & $\mathrm{p}$-value \\
\hline 2 abnormalities in 2 nerves & 0 & 5 & 0.055 \\
\hline 2 abnormalities in 3 nerves (mononeuritis multiplex) & 0 & 1 & 1 \\
\hline $\begin{array}{l}2 \text { abnormalities in at least 3 symmetrical nerves } \\
\text { (polyneuropathy) }\end{array}$ & 0 & 0 & - \\
\hline
\end{tabular}

Table 3. Comparison of means for different nerve features and their results

\begin{tabular}{|c|c|c|c|}
\hline Nerve & Group & Mean \pm SD & p-value \\
\hline \multirow[t]{2}{*}{ Median motor amplitude (mv) } & Case & $8.33 \pm 1.74$ & \multirow[t]{2}{*}{0.226} \\
\hline & Control & $8.65 \pm 1.47$ & \\
\hline \multirow[t]{2}{*}{ Median motor latency (ms) } & Case & $3.763 \pm 0.26$ & \multirow[t]{2}{*}{0.900} \\
\hline & Control & $3.758 \pm 0.24$ & \\
\hline \multirow[t]{2}{*}{ Median sensory amplitude ( $\mu \mathrm{v})$} & Case & $22.401 \pm 4.48$ & \multirow[t]{2}{*}{0.058} \\
\hline & Control & $23.667 \pm 3.74$ & \\
\hline \multirow[t]{2}{*}{ Median sensory latency (ms) } & Case & $3.357 \pm 0.18$ & \multirow[t]{2}{*}{0.838} \\
\hline & Control & $3.351 \pm 0.16$ & \\
\hline \multirow[t]{2}{*}{ Median conduction velocity (sensory) $(\mathrm{m} / \mathrm{s})$} & Case & $52.04 \pm 3.46$ & \multirow[t]{2}{*}{0.220} \\
\hline & Control & $52.22 \pm 2.72$ & \\
\hline \multirow[t]{2}{*}{ Ulnar motor amplitude (mv) } & Case & $7.399 \pm 0.92$ & \multirow[t]{2}{*}{0.215} \\
\hline & Control & $7.446 \pm 1.13$ & \\
\hline \multirow[t]{2}{*}{ Ulnar motor latency (ms) } & Case & $2.79 \pm 0.27$ & \multirow[t]{2}{*}{0.903} \\
\hline & Control & $2.79 \pm 0.25$ & \\
\hline \multirow[t]{2}{*}{ Ulnar sensory amplitude $(\mu v)$} & Case & $21.132 \pm 3.94$ & \multirow[t]{2}{*}{0.070} \\
\hline & Control & $22.492 \pm 3.67$ & \\
\hline \multirow[t]{2}{*}{ Ulnar sensory latency (ms) } & Case & $2.776 \pm 0.31$ & \multirow[t]{2}{*}{0.064} \\
\hline & Control & $2.687 \pm 0.27$ & \\
\hline \multirow[t]{2}{*}{ Tibial motor amplitude (mv) } & Case & $5.243 \pm 1.27$ & \multirow[t]{2}{*}{0.068} \\
\hline & Control & $5.558 \pm 1.00$ & \\
\hline \multirow[t]{2}{*}{ Tibial motor latency (ms) } & Case & $4.60 \pm 0.56$ & \multirow[t]{2}{*}{0.169} \\
\hline & Control & $4.71 \pm 0.40$ & \\
\hline \multirow[t]{2}{*}{ Tibial conduction velocity (motor) $(\mathrm{m} / \mathrm{s})$} & Case & $42.67 \pm 2.25$ & \multirow[t]{2}{*}{0.610} \\
\hline & Control & $42.83 \pm 1.79$ & \\
\hline \multirow[t]{2}{*}{ Peroneal motor amplitude (mv) } & Case & $2.763 \pm 1.06$ & \multirow[t]{2}{*}{0.048} \\
\hline & Control & $2.515 \pm 0.64$ & \\
\hline \multirow[t]{2}{*}{ Peroneal motor latency (ms) } & Case & $4.45 \pm 0.63$ & \multirow[t]{2}{*}{0.827} \\
\hline & Control & $4.43 \pm 0.60$ & \\
\hline \multirow[t]{2}{*}{ Peroneal conduction velocity (motor) $(\mathrm{m} / \mathrm{s})$} & Case & $48.09 \pm 4.62$ & \multirow[t]{2}{*}{0.151} \\
\hline & Control & $47.15 \pm 3.38$ & \\
\hline Sural amplitude $(\mu \mathrm{v})$ & Case & $8.15 \pm 1.91$ & 0.036 \\
\hline & Control & $9.03 \pm 2.72$ & \\
\hline Sural latency (ms) & Case & $3.601 \pm 0.50$ & 0.134 \\
\hline & Control & $3.519 \pm 0.49$ & \\
\hline
\end{tabular}

mv: millivolt; ms: millisecond; m/s: meter/second; $\mu \mathrm{v}$ : microvolt; SD: Standard deviation 


\section{Discussion}

In this study, no significant differences were observed between the groups regarding any of the definitions for peripheral neuropathy. However, the p-value $(0.055)$ was close to significance for the first criteria [2 abnormalities (velocity, amplitude, latency) in 2 nerves]. Comparison of the mean differences for nerve features between the two groups revealed that only in two features obvious differences were observed: amplitude of the peroneal motor nerve $(p=0.048)$ and amplitude of the sural sensory nerve $(p=0.036)$. In four features, including amplitude of the median sensory nerve $(p=0.058)$, amplitude of the ulnar sensory nerve $(p=0.070)$, amplitude of the tibial motor nerve $(p=0.068)$ and latency of the ulnar sensory nerve $(p=0.064)$, even though the differences were not statistically significant, they might have become significant, had the study been conducted on a higher number of cases or among patients with longer periods of drug consumption. Since most of the differences were in amplitudes and the relative nerves were related to lower limbs, we can assume that these drugs mostly affected the axonal fibers and had little effect on the myelin sheaths of the studied nerves. These findings were consistent with our previous knowledge regarding the probability of peripheral neuropathy following drug consumption (axonal neuropathy) (1, 20, 21). Brenton West found that the prevalence of this type of neuropathy was 4-14 times higher among patients using statins (22) Gaist stated that patients on statins are 2.5 times more susceptible to polyneuropathy in comparison with the normal population (23). In a prospective study with electrodiagnostic follow-up, Pavel Otruba evaluated the peripheral nerves of the lower limbs among 42 patients with hyperlipidemia at the beginning of the statin consumption period and then at the $6^{\text {th }}, 12^{\text {th }}$ and $24^{\text {th }}$ month, using the NCS criteria (tibial, peroneal, sural and superficial peroneal nerve features); at the end, they only found significant differences in the nerve conduction latency of the F wave for motor nerves, and concluded that "long-term use of statins could make visible changes in electrophysiological findings; however, these probable changes are clinically silent" (12). However, they did not evaluate the nerve response latency in their study. In the present study, even though we did not evaluate the F wave, nerve response latency was studied in the sensory and motor nerves of the upper and lower limbs; however, none of them showed a significant difference. In a cohort study, Davis showed that statin consumption could prevent distal sensory neuropathy in diabetic individuals. In their study, they used the Michigan Neuropathy Screening Instrument (MNSI) as the criteria for neuropathy (24). Nonetheless, it seems that future studies should use electrodiagnosis to confirm their findings. Conversely, in another study, Vaughan TB introduced a patient with type 1 diabetes (without any hyperlipidemia) who was on atorvastatin and had developed axonal sensory, motor and autonomic peripheral neuropathy. After discontinuation of the drug, the patient showed a significant clinical recovery in one week (16). One case of mononeuritis multiplex was observed in our case group based on the normal values presented in Table 1. However, that patient did not have any clinical complaints regarding peripheral neuropathy. There have been other case reports involving this phenomenon following statin consumption; for instance, Menahem introduced a patient who consumed simvastatin for approximately three years which had developed meralgia paresthetica, but after a few weeks being off the drug, the patient's symptoms vanished completely (25). Rosana H. Scola et al. found this phenomenon in a 63-year-old man following high doses of simvastatin; this patient had sensory and motor complaints (26). In an animal study on rats, Nitya N. Pathak revealed atorvastatin to be effective in neuropathic pain reduction. This effect is caused by changes in enzymatic and non-enzymatic systems of antioxidants (malondialdehyde and super-oxide anions are reduced following atorvastatin consumption) (11). Furthermore, through sympathetic skin response (SSR) testing, Ziajka reported the occurrence of peripheral neuropathy in thin fibers following statin consumption, and showed the test results to return to normal after drug cessation (27). In our study, we used the conventional techniques for nerve conduction, which only evaluates large nerve fibers, but the SSR test can be used to evaluate thin fibers. Most reports on statin-induced neuropathy propose the improvement of clinical symptoms and electrophysiological tests after stopping the drug; however, Jeppesen stated that symptoms had lasted longer in four out of seven patients with the disease, by using quantitative sensory testing (QST); he had presumed that the probable cause was longer periods of consumption or longer periods of having symptoms before being cut off (28).

\section{Conclusions}

With regard to the above-mentioned findings, it can be concluded that statin consumption can cause changes in the peripheral nerves with a preference of axonal involvement; however, in many cases, these changes are not significant enough to cause visible clinical symptoms, especially when the consumption period is not that long. Considering the variety of reports regarding the effects of these drugs on the peripheral nerves, we suggest further, more extensive studies on patients with long-term statin consumption using different methods of peripheral nerve evaluation such as NCS, QST, and SSR. A limitation of this study was the small number of patients. Also, we recommend that patients with long-term use should become aware of this condition's symptoms and visit their doctors for diagnostic evaluations; we also recommend that the physicians should ask questions regarding these 
symptoms in their regular check-ups. Also, future studies can focus on larger samples. As the prevalence of neuropathy was generally low in our sample population, application of inverse sampling method could yield more reliable results. We could not predict this point before conduction of the study and therefore it is suggested for future studies.

\section{Acknowledgments:}

The authors would like to thank the Research Consultation Center (RCC) of Shiraz University of Medical Sciences for their invaluable assistance in analyzing the data and editing the manuscript. This study is a part of thesis of Hosein Arjmand (Grant no: 1941). The authors also would like to thank the Center for Development of Clinical Research at Nemazee Hospital for editorial assistance.

\section{Conflict of Interest:}

There is no conflict of interest to be declared.

Authors' contributions:

All authors contributed to this project and article equally. All authors read and approved the final manuscript.

\section{References:}

1) Weimer LH. Medication-induced peripheral neuropathy. Curr Neurol Neurosci Rep. 2003; 3(1): 86-92. doi: 10.1007/s11910-003-0043-8. PMID: 12507417.

2) Burns JM, Mauermann ML, Burns TM. An easy approach to evaluating peripheral neuropathy. J Fam Practice. 2006; 55(10): 853-65. PMID: 17014750.

3) Backes JM, Howard PA. Association of HMG-CoA reductase inhibitors with neuropathy. Ann Pharmacother. 2003; 37(2): 274-8. doi: 10.1177/106002800303700220.

4) De Langen JJ, Van Puijenbroek EP. HMG-CoA-reductase inhibitors and neuropathy: reports to the Netherlands Pharmacovigilance Centre. Neth J Med. 2006; 64(9): 334-8. PMID: 17057271.

5) Donaghy M. Assessing the risk of drug-induced neurologic disorders Statins and neuropathy. Neurology. 2002; 58(9): 1321-2. doi: 10.1212/WNL.58.9.1321.

6) Chong PH, Boskovich A, Stevkovic N, Bartt RE. Statin - Associated Peripheral Neuropathy: Review of the Literature. Pharmacotherapy. 2004; 24(9): 1194-203. doi: 10.1592/phco.24.13.1194.38084.

7) Corrao G, Zambon A, Bertù L, Botteri E, Leoni O, Contiero P. Lipid lowering drugs prescription and the risk of peripheral neuropathy: an exploratory case-control study using automated databases. J Epidemiol Community Health. 2004; 58(12): 1047-51. doi: 10.1136/jech.2003.013409.

8) West B, Williams C, Jilbert E, James A, Haines T. Statin use and peripheral sensory neuropathy: a pilot study. J Foot Ankle Res. 2013; 6(1): 40. doi: 10.1186/1757-1146-6-S1-O40. PMCID: PMC3668969.

9) Jones B, Ball G, Feher MD. Statins and peripheral neuropathy: causation or coincidence? Br J Diabetes Vasc Dis. 2011; 11(1): 38-9. doi: 10.1177/1474651410394768.

10) Graveline D. Adverse Effects of statin drugs: a physician patient's perspective. J Am Phys Surg. 2015; 20: 7-11.

11) Pathak NN, Balaganur V, Lingaraju MC, Kant V, Latief N, More AS, et al. Atorvastatin attenuates neuropathic pain in rat neuropathy model by down-regulating oxidative damage at peripheral, spinal and supraspinal levels. Neurochem Int. 2014; 68: 1-9. doi: 10.1016/j.neuint.2014.01.014.

12) Otruba P, Kanovsky P, Hlustic P. Treatment with statins and involvement of peripheral nervous system: results of a prospective clinical and neurophysiological follow-up. Biomed pap med fac univ palacky olomouc Czech Repub. 2007; 151: 307-10. PMID: 18345269.

13) Chaitow L. Muscle pain and use of statin drugs. J Bodyw Mov Ther. 2014; 18(2): 149-50. doi: 10.1016/j.jbmt.2014.02.001.

14) Bosomworth NJ. Statin Therapy as Primary Prevention in Exercising Adults: Best Evidence for Avoiding Myalgia. J Am Board Fam Med. 2016; 29: 727-40. doi: 10.3122/jabfm.2016.06.160085.

15) Gaist D, Jeppesen U, Andersen M, Garcia Rodrigueez LA, Hallas J, Sindrup SH. Statins and risk of polyneuropathy. Neurology. 2002; 58: 1333-7. doi: 10.1212/WNL.58.9.1333.

16) Vaughan TB, Bell DS. Statin neuropathy masquerading as diabetic autoimmune polyneuropathy. Diabetes Care. 2005; 28(8): 2082. doi: 10.2337/diacare.28.8.2082.

17) Kalra S, Agrawal N, Kalra B, Sharma A, Kamboj R. The role of Coenzyme Q10 in statin-associated myopathy. Electron Physician. 2009; 1: 2-8. 
18) Dumitru D, Amato A. Approach to peripheral neuropathy. Electrodiagnostic medicine. 2nd ed. Philadelphia: Hanley \& Belfus; 2002: 194-217.

19) Preston DC, Shapiro BE. Electromyography and Neuromuscular Disorders, Clinical-Electrophysiologic Correlations. 2nd ed. Elsevier; 2005: 117-59.

20) Phan T, Mclead JG, Pollard JD, Peiris O, Rohan A, J-P Halpern. Peripheral neuropathy associated with simvastatin. J Neurol Neurosurg Psychiatry. 1995; 58: 625-8. doi: 10.1136/jnnp.58.5.625.

21) Vilholm OJ, Christensen AA, Zedan AH, Itani M. Drug - Induced Peripheral Neuropathy. Basic Clin Pharmacol Toxicol. 2014; 115(2): 185-92. doi: 10.1111/bcpt.12261.

22) West B. The implications of statin induced peripheral neuropathy. J Foot Ankle Res. 2011; 4(1): 57. doi: 10.1186/1757-1146-4-S1-P57.

23) Gaist D, Huerta C, Hallas J, Sindrup S. Are users of lipid-lowering drugs at increased risk of peripheral neuropathy? Eur J Clin pharmacol. 2001; 56: 931-3. doi: 10.1007/s002280000248.

24) Davis TM, Yeap BB, Davis WA, Bruce DG. Lipid-lowering therapy and peripheral sensory neuropathy in type 2 diabetes: the Fremantle Diabetes Study. Diabetologia. 2008; 51(4): 562-6. doi: 10.1007/s00125-0070919-2.

25) Menahem S, Shvartzman P. Simvastatin-induced meralgia paresthetica. J Am Board Fam Med. 2011; 24(4): 469-73. doi: 10.3122/jabfm.2011.04.100229.

26) Scola RH, Trentin AP, Germiniani F, Piovesan ÉJ, Werneck LC. Simvastatin-induced mononeuropathy multiplex: case report. Arq Neuropsiquiatr. 2004; 62(2B): 540-2. DOI: 10.1590/S0004282X2004000300031.

27) Ziajka PE, Wehmeier T. Peripheral neuropathy and lipid-lowering therapy. South Med J. 1998; 91(7): 6678. doi: 10.1097/00007611-199807000-00013. PMID: 9671841.

28) Jeppesen U, Gaist D, Smith T, Sindrup SH. Statins and peripheral neuropathy. Eur J Clin Pharmacol. 1999; 54(11): 835-8. DOI: $10.1007 / \mathrm{s} 002280050562$. 